\title{
Avaliação das políticas públicas na França
}

Nicoletta Stame Meldolesi

\section{Introdução}

Em 1990, a França colocou em funcionamento um sistema interministerial de avaliação das políticas públicas.

Esta decisão foi resuitado de uma discussão de dez anos sobre a reforma do Estado e, ao mesmo tempo, o encaminhamento de uma experiência, que, embora ainda reduzida, parece destinada a criar raizes. Vem, assim, da França — um país que nos é culturalmente semelhante, mas cujas instituições vêm sempre sendo observadas com uma reverência que esconde com dificuldade o pouco caso, para não dizer bloqueio mental - um exemplo encorajador para todos os paises do Welfare State: um exemplo que quisemos explorar pela sua racionalidade e capacidade de responder às exigências mais profundas.

$\mathrm{O}$ que impressiona nesta experiência é o modo pelo qual, convencidos da importância da avaliação e tendo examinado os vários aspectos, um determinado grupo de pessoas de diversos meios políticos e de várias origens institucionais conseguiu, com espirito pluralista, dar vida a uma realidade bi-partisan, que modifica significativamente o sistema legislativo, tanto no processo de decisão quanto no de implementação. Essas pessoas conseguiram apresentar sua proposta em ambientes especializados ou não, utilizando uma série de revistas (como Le Débat, Commentaire, Revue française de science politique, Projet, Problèmes politiques et sociaux, Revue française d'administration publique) interferindo nas mais diversas ocasiões, de forma a tornar palpável uma prática que aperfeiçoe as condições nas quais se desenvolve a ação coletiva e comprometa funcionários públicos e usuários a assumirem a responsabilidade de

Nicoletta Stame Meldolesi es Professora de Ciência Política da Universidade de Messina, Itália 
fazer o Estado funcionar. A isso acrescenta-se o papel desempenhado pelas altas autoridades da República, que souberam colher frutos do debate e dar impulso à reforma, permitindo o desenvolvimento da experiência prática.

Naturalmente, ainda é cedo para falar de um aparato de avaliação sólida e estabelecido; mas o mecanismo muito simples e barato, que foi provado, já permitiu a vários atores de políticas públicas fazer as primeiras experiências importantes, que souberam levar adiante, nos mais diversos setores da administração, descobrindo novas potencialidades. É significativo que conseguissem transmitir suas experiências, e que destes exemplos extraissem uma surpreendente vitalidade.

Nas páginas que seguem, reconstituiremos, portanto, em primeiro lugar, as diversas posições que alimentaram o debate e o modo pelo qual interferiram nas propostas de reforma e nas novas realidades institucionais. Em seguida, esclareceremos como o mecanismo em funcionamento pode favorecer, por sua vez, um novo diálogo, e possibilitar, assim, um melhor funcionamento do sistema democrático.

\section{A crise de uma boa administração}

A França do pós-guerra caracterizou-se por uma política dirigida e solidária, que pôde se apoiar em uma Administração Pública eficiente, com capacidade tradicionalmente reconhecida de agregar os interesses particulares (MıNELLI, 1989). A intervenção pública na economia adquiriu consistência em diversos graus de programação.

Nos anos 50 e 60, foi imposto um acordo entre o plano estatal e as empresas. Era o momento da reconstrução e da atenção para com as quantidades; mas, mesmo assim, não faltaram críticas, a pretexto de controlar tudo, e apelos a um maior reconhecimento da diversidade (CROZIER, 1967).

Nos anos 70, começou-se a falar mais da racionalidade nas escolhas de programações do que de plano, e os métodos americanos de análise foram estudados ex ante (o Planning Programming Budgeting System), procurando, porém, manter a especificidade francesa de um maior direcionamento público (que deveria ser refletido no método da Rationnalité des choix budgetaires, Rcb, cfr. MULLER, 1990, p.114). Na realidade, simplesmente, foram colocados em funcionamento os mecanismos de análise custo-benefício para a escolha dos investimentos. Paralelamente, foram elaborados métodos de análise próprios ex ante dos projetos de desenvolvimento na cooperação internacional (o método dos efeitos), que por seu centralismo mais acentuado e coordenação teriam que se diferenciar daqueles mais difundidos pelas agências internacionais, divulgados 
nos manuais de LITTLE \& MirLeEs e de OnUDI (cfr. Ministère de la coopération, 1976).

Com todos esses desenvolvimentos, era sempre mantida a tradição administrativa francesa, caracterizada por uma forte centralização, elevado profissionalismo nos niveis superiores (graças à formação dos dirigentes nas Grandes écoles e, em particular, na ENA, École Nationale d'Administration, de onde vem a denominação "enarcas"), presença de instituições de controle administrativo (a Cour des comptes) e financeiro (a Inspection des finances) particularmente eficazes nas suas inspeções e, enfim, um corpo de funcionários de nível inferior educado no espírito do serviço público. Não nos surpreende que se pudesse, tranqüilamente, afirmar que o Estado era o depositário do interesse público.

Vista retrospectivamente, esta parece a época da "simplicidade" e da "homogeneidade", na qual se pensa ser possivel conhecer as necessidades da sociedade e prever as soluções que funcionarão. Em outras palavras, governar a sociedade através da realização do plano e da legitimidade dos decretos. Eé, também, a oportunidade de ampliar a intervenção do Estado até a cobertura, cada vez mais ampla, do risco social: os franceses traduziram o Welfare State, basicamente, como État providence.

O brusco despertar que, no fim dos anos 70 , a crise fiscal do Welfare State provoca em todos os paises industrializados, obrigando a cortar os orçamentos públicos que crescem desmedidamente, embora oferecendo serviços de pior qualidade, recebe na França um contragolpe diferente. A maior parte das sociedades do Bem-Estar, atingidas por uma crise do modelo do conhecimento (não podemos identificar nem prever o desenvolvimento de uma sociedade complexa e diversificada, na qual tudo é interdependente), provocaram uma reação contra o Estado, nos seus dois instrumentos: o plano que não poderia alocar os recursos de modo racional (ineficiência); e a Administração Pública, que não teria condições de exercer a administração de modo justo e imparcial (crise de legitimidade). E são as sociedades com caracteristicas estatistas mais frágeis que vêem surgir as ideologias do "Estado Mínimo" e os debates sobre "Estado-mercado" e "mais ou menos Estado".

Também atingida por esta crise, a França reage apoiando-se na sua tradição estatizante. Os cortes no orçamento ocorrem de modo gradual e silencioso e, sobretudo, nunca estão estreitamente ligados às profundas inovações que afetam diretamente o Estado.'

Aqui nunca é seriamente all'odg o problema do Estado Minimo; mesmo que não se tenha dado conta da crise do Éat providence (ROSANVALLON, 1981), a situação foi sentida como ocasião para um grande trabalho de modernização do Estado. O primeiro-ministro Rocard sintetizou esta política, cunhando a fórmula da procura do mieux d'érar - uma fórmula que devolve a confiança à Administração Pública em vez de san- 
cioná-la. Esta deve procurar reconquistar uma legitimidade, não insistindo na tradição monarquista e estatiste, mas, principalmente, renovando a sua atitude e capacidade de realizar melhor que a iniciativa privada a missão que the foi confiada.

Durante os anos 80 , esta tendência toma dois caminhos principais. O primeiro - do qual não nos ocuparemos nestas notas - ataca a rigidez dos órgãos da Administração Pública e promove a descentralização (que aumenta os poderes das coletividades locais e do Legislativo, em prejuizo da administração central e do Executivo) e a desconcentração (que reorganiza, a nivel local, os escritórios estatais), duas reformas aprovadas por uma lei de $1982 .^{2}$

O segundo - que é o objeto da nossa análise - diz respeito à rigidez dos instrumentos de intervenção do Estado: em vez de criar planos e decretos, começa-se a considerar que um Estado moderno deva governar através de políticas públicas e programas a realizar, uma vez que a sua avaliação tenha evidenciado discrepâncias entre objetivos e resultados, através de um processo incrementador que diz respeito tanto à atuação como à decisão.

Sendo assim, se o tema é remediar a crise do Estado, a ênfase é dada primeiro à avaliação e depois às políticas públicas a serem avaliadas, uma peculiar e frutífera inversão de seqüência. No sistema americano de Common Law, foi uma cultura jurídica baseada na flexibilidade e na adaptação que favoreceu o aparecimento de programas sociais, sobretudo a partir da War on Poverty, que se ocupava dos problemas que estavam no centro do movimento pelos direitos civis. Os programas sociais são projetos de reforma que - seguindo uma particular hipótese de mudança - se comprometem a obter determinados objetivos em um determinado lapso de tempo, com os meios fornecidos por uma determinada dotação no orçamento: seja para confrontar os resultados obtidos com os objetivos prefixados, seja para decidir o que fazer no fim do periodo ("prosseguir ou abandonar o programa; melhorar as suas práticas e procedimentos; acrescentar ou abandonar técnicas e estratégias; instituir programas similares em outros lugares; distribuir os recursos entre programas concorrentes; aceitar ou recusar a aproximação de um programa e de suas hipóteses" - como lembra Weıss, Carol, 1992, p. 16), desenvolveram vários métodos de avaliação, que diferem quanto ao objetivo, modelo e destinatários.

No sistema francês, para o ato administrativo, no qual a norma é vista como solução estável e justa para problemas recorrentes, foi preciso rever os resultados não satisfatórios (sempre indicados erroneamente com a fórmula dos "efeitos perversos") $)^{3}$ e encontrar novos caminhos, através da avaliação para fazer com que o instrumento legislativo tomasse a forma mais ágil e pragmática dos programas e das políticas públicas. 
Naturalmente, surgiram diversos pontos de vista. Alguns sustentam que somente as politicas que se baseiam em programa precisos, fundos para administrar e metas específicas a seguir, e que só estas podem ser avaliadas: assim, insistem para que a legislação evolua para a formulação de programas inovadores. Outros propõem uma inversão de seqüência: avaliar pode ajudar a encontrar uma maior coerência (e dignidade das políticas públicas), mesmo com ações legislativas concebidas como ações desligadas e setoriais, que, porém, contribuem para enfrentar problemas complexos: é o típico caso da política urbana. ${ }^{4}$ Assim, em um dos primeiros encargos de avaliação que the é confiado - intitulado "As políticas sociais transversais: uma metodologia dos seus efeitos locais" o Comissariat général du plan (1986) pede a um grupo de trabalho misto (de internos e externos) para contribuir para a definição de um dispositivo de avaliação das políticas sociais locais e define como política pública o conjunto destes programas de "desenvolvimento social dos bairros periféricos", cujos efeitos se fazem sentir sobre aspectos como o cumprimento da obrigatoriedade escolar, a desocupação juvenil, etc.

Em 1989, Meny, Yves e Thornic, Jean Claude, em seu influente manual, deram uma definição pragmática, mas ainda fora do contexto das políticas públicas e da avaliação: "Se a política pública é uma série de hipóteses ou uma teoria, afirmada e sustentada por um órgão governamental, avaliar consiste em descobrir as surpresas que a ação gera em relação àquela teoria" (p. 307). Poucos anos depois, DurAn, Patrice e MONNIER, Eric (1992, p. 245-246), graças à familiaridade com um modelo de avaliação pluralista, que vai se impor no início da década de 90 (e que, como veremos, envolve políticos, funcionários, avaliadores e público interessado em um confronto com a política avaliada), qualificam o aspecto cognitivo das políticas públicas como o fruto de um processo coletivo de conhecimento: através do acordo iterativo e interativo entre os atores decorrente da avaliação, a incerteza pode ser compreendida como componente que não pode ser eliminado da ação, na definição de problemas e soluções que se colocam sempre de uma maneira nova. "A avaliação não é mais vista somente como um simples momento de desenvolvimento de uma política pública, da qual é, de alguma maneira, parte integrante" (DURAN \& MONNIIR, 1992, p. 246). Toda a matéria encontrará sua sistematização em um número da Revue française de science politique, intitulada "Politiques publiques en France", na qual a passagem dos anos 80 é descrita como o abandono da especificidade francesa, que mantinha o Estado protegido de uma análise científica, por uma evolução para o estudo do "Estado em ação", que opera através de políticas públicas, ou modos de "governar" das sociedades complexas (COHEN \& MULLER, 1992). ${ }^{5}$

Agora, porém, esta definição, que reflete tão bem o significado do 
passado, talvez não faça justiça à especificidade francesa do presente que - a meu ver - consiste em procurar dar aquele passo junto à Administração Pública. Esta última, pelo menos em alguns de seus setores importantes, compreendeu a necessidade de se interrogar sobre a atividade desenvolvida para poder se reconciliar com a própria história. Não quero dizer com isto que a avaliação tenha agido de forma indolor sobre o "corpo" social do Estado, mas que as resistências naturais manifestadas inicialmente se mostraram menos graves que o previsto.

A questão, porém, persistiu por muito tempo e manteve os protagonistas em suspenso em relação aos seus possiveis êxitos. Teria sido a Administração Pública tão forte a ponto de boicotar a avaliação? Nesse caso, seria preciso enganá-la, como por exemplo avaliando políticas nas (̣ıais não estava interessada (as politicas redistributivas em relação às normativas). Ou, então, teria sido capaz de se auto reformar e aceitar a avaliação? Então, seria preciso convencê-la.

Foi recolhido, em 1991, um interessante testemunho do Prof. Jean Leca. ${ }^{\circ}$ A Administração Pública - disse ele - tinha que aceitar a idèia de não ser mais aquela "ordem monástica" (L'état prêtre, de Marx) que se ocupa da desgraça alheia, aquele instrumento eficaz que resolve os problemas colocados pela sociedade, mas ser, ela própria, um problema. E dever-se-ia poder analisar o comportamento da administração e objetivá-lo para qualquer grupo social.

Leca via, então, dois tipos de resistência colocados ao avanço da idéia da avaliação por parte dos "enarcas" franceses. O primeiro decorre do "modelo do conhecimento", que faz deles "ignorantes": de fato, eles demonstram ser uma "tribo", que conhece e entende somente a linguagem dos indigenas, alheios ao mundo externo. Assim, pensam que se se deve fazer avaliação, existem alguns modos já conhecidos (ou, em outras palavras, "a avaliação, nós jả a fazemos"). Porém, quais seriam esses modos? O controle e as comissões parlamentares de inquérito são outra coisa. O controle é de legitimidade (verifica-se se foram cumpridos os atos previstos na norma estabelecida) e financeiro (verifica-se como foi gasto o dinheiro, no pressuposto de que o dinheiro bem usado é aquele que não foi gasto). Ao contrário, a avaliação serve exatamente para ir além desses limites: serve para sabermos quais atos foram cumpridos além da previsão, quais foram as conseqüências inesperadas; se as despesas previstas obtiveram resultados positivos. Quanto às investigações parlamentares, não são outra coisa senão indagações à espera de soluções propostas pelas várias facções políticas, e não alcançam nunca a dignidade de uma nova sugestão baseada na experiência sobre a qual tenha havido consenso.

Essa posição conservadora - acrescenta Leca - vem de um outro "desvio profissional" dos altos funcionários: eles são administradores 
que consideram a avaliação simplesmente uma sociologia, ou seja, uma "pseudo-consciência" à qual se recorre quando é preciso entender "o que o povo pensa" (e não têm idéia alguma dos problemas teórico-metodológicos que este tipo de pesquisa envolve). No entanto, eles têm o segundo tipo de resistência de caráter mais prático: têm medo de que a avaliação esteja ligada a uma sanção, ou seja, se as coisas correram mal que sejam eles a pagar, enquanto se tudo der certo, o mérito vá para o legislador.

Como veremos, pouco a pouco, as coisas vão se desenvolvendo graças também a uma acertada politica governativa que apresentou a avaliação como procura de colaboração e consenso - tais objeções deram lugar a um envolvimento um pouco incerto e, depois, a uma consciência de responsabilidade mais precisa, pelo menos por parte de algumas administrações, que souberam dar um significado positivo às suas ações.

\section{O debate sobre a avaliação}

A importância da avaliação nesta fase da crise do Estado é bem sintetizada por CrozıER, Michel em État modeste, état moderne (1987), um trabalho que assinala uma reviravolta no panorama intelectual francês.

O Estado moderno - segundo esse autor - evoluiu de um grupo restrito de funcionários, que se ocupavam exclusivamente da ordem pública e da defesa, para o Estado do Bem-Estar, que fornece serviços públicos aos cidadãos de modo igual e massificado. Porém, o Estado moderno se encontra diante de uma sociedade complexa, que apresenta necessidades diversificadas e de qualidade, que não podem ser absolvidas pelas políticas estatais. Assim, se ele se detivesse no velho modelo de satisfação das necessidades, não poderia senão ser autoritário e arrogante, além de irracional na maneira de alocar os próprios recursos. Dai, segundo Crozier, a exigência de que o Estado aprenda a ser modesto. O que significa: escolher bem os setores nos quais deverá intervir, valorizar os recursos humanos presentes entre os funcionários e os colocar a serviço dos usuários, além de solicitar a participação dos usuários e a responsabilização dos empregados com o objetivo de usar o dinheiro público sem desperdícios. Porém, um Estado que se proponha estes objetivos deve estar em condições de conhecer e comparar os resultados de diversas políticas e a prática constante da avaliação é seu requisito fundamental.

Uma vez aberto o campo dos estudos franceses à exigência da avaliação, desenrola-se um debate que tende a definir os contornos entre funcionários públicos, políticos de centro (em volta de Mehaignerie), de centro-esquerda (Barre), de esquerda moderada (Rocard) e pesquisadores acadêmicos ou dos escritórios de estudo dos ministérios. 
Uma primeira abordagem é a de estudar as experiências de outros países e os resultados obtidos com a avaliação. Entre os anos de 1983 e 1988, houve uma sucessão de seminários e encontros de estudos nos quais se confrontaram os sistemas europeus (Suécia, Inglaterra e Alemanha), americanos e japoneses. ${ }^{7} \mathrm{O}$ que interessava principalmente nessa época era o aspecto institucional (que estruturas existem nestes países? qual é o papel do avaliador?) e o metodológico (como se faz a avaliação?), tudo sintetizado na resposta às famosas cinco perguntas que cada avaliação devia fazer: "quando?", “onde?", "por quê?", "para quem?" e "o quê?". E as publicações eram cheias de tipologias e de discussões sobre as opções metodológicas. ${ }^{8}$

A situação que despertou maior interesse foi a dos Estados Unidos, onde a experiência de avaliação pluridecenal das políticas públicas (GUBA \& LINCOLN, 1989, falam de quatro gerações de avaliação) ${ }^{9}$ firmou-se graças à tradição pragmática e empírica da cultura americana e ao prestígio que o organismo do Congresso soube conquistar no que se refere a esta função: o General Accouting Office (Gao) e a Program EvaInation Methodology Division, dirigida por Eleanor Chelimsky. ${ }^{10} \mathrm{Em}$ particular, foram atentamente estudadas neste periodo as origens da "experiência social" (CAMPBELL, 1969): discutiram-se projetos particulares, como o da imposição negativa de New Jersey ou do Great Housing Experiment (MONNIER, 1987, p. 39 e 65) e o debate sobre a implementation (Pressman \& Wildavsky, 1973; Bardach, 1977).

Inicialmente, prevalece uma opinião mais gerencial," remédios para a ineficiência do Estado (visto como fornecedor dos bens públicos) na comparação entre o modo como Estado e empresas fornecem os respectivos serviços ao público. $O$ argumento que vem sendo usado é o da diferença dos controles entre empresas e Estado: enquanto as empresas são sujeitas ao controle de qualidade imposto pela concorrência, sob pena de desaparecer do mercado, o Estado poderia se perpetuar na ineficiência, pela falta de um controle equivalente. Mas o remédio - este é o ponto - teria sido inventado, e é o da avaliação, que permite ao Estado comparar os efeitos obtidos com os objetivos prefixados e corrigir as eventuais alterações. Conforme este paralelo, leva-se adiante a idéia de que tudo depende da avaliação das políticas (equiparada à clareza dos objetivos e sua tradução em indicadores que possam fornecer a base para um confronto experimental).

Pode-se dizer que o espírito deste periodo esteja bem representado pelo relatório do Commissariat Général du Plan de Deleau (1986), que dizia, entre outras coisas, que avaliar uma política significa reconhecer e medir seus efeitos. É uma colocação que favorece as temáticas da eficiência das políticas públicas e um melhor uso do orçamento, que se encontra impedido na complexidade da situação observada. 
Esta formulação trouxe consigo a proposta do modelo "experimental" - considerado modelo "científico" por excelência - que se baseia na mensurabilidade e validade externa dos resultados (reprodutibilidade), e que recorre, sobretudo, ao trabalho de consultores externos, que devem ser experts nas técnicas de avaliação (sondagens, os quase-experimentos, etc.) e objetivos (ou seja, independentes).

Desse modo, embora a idéia da avaliação se tornasse conhecida como uma maneira de enfrentar a crise do Estado, ela envolvia apenas dois tipos de atores: os politicos enquanto (e na medida em que) aceitassem a exigência de uma forma diferente de atuação (fazer programas em lugar das leis de principio) e os avaliadores, especialistas externos cuja característica principal seria a de serem detentores de uma metodologia. Deixava-se, ao invés, à sombra, a contribuição da função pública; isto por uma espécie de subavaliação de seu valor (menor do que o dos que decidem e o dos especialistas) e da pouca consideração por sua capacidade de reforma.

Esta atitude encontra espetacular correspondência na posição de recusa da avaliação por parte dos "enarcas", descrita por Leca. Eles podem perfeitamente dizer que a avaliação é inútil, porque não traz resultados concretos, e baseia-se em uma expertise pouco rigorosa (a sociologia, como ciência pouco exítta, em contraposição ao direito administrativo e econômico, doutrinas mais duras já em uso junto à administração). Porém, pode-se também encontrar a aquiescência de alguns funcionários que, não podendo se opor à avaliação, acham, porém, que ela deva ser confiada a especialistas e não querem ser condicionados.

A posição da administração é rapidamente contraposta a uma posição diferente, baseada em uma característica da avaliação, que é a de ser um "instrumento de qualidade democrática" (VIVERET, 1989 e 1991) e que vincula a avaliação à solução dos problemas políticos nacionais. $\mathrm{O}$ tema foi abordado pela primeira vez pelo Obsenvatoire de la decision publique (uma associação dos cidadãos organizada por Patrick Viveret) na Convenção "La démocratie dans la société complexe" organizada pelo Nouvel Observateur, em 1986. O problema ao qual se refere é o de superar a ausência do pluralismo de uma situação, na qual prevalece o monopólio da expertise caracteristica das grandes corporações. Isso significa, antes de tudo, garantir a publicidade e a transparência das avaliações, para favorecer um esclarecimento do debate público sobre as grandes opções da ação governativa (a este propósito são freqüentemente lembrados os dois Artigos da Declaração dos Direitos Humanos, precursores, poder-se-ia dizer, da avaliação ex-ante concomitante à ex-post, o Art. 14, que estipula que os cidadãos possam constatar a necessidade da sua contribuição fiscal e controlar [suivre] o seu uso; Art. 15, segundo o qual "a sociedade tem direito de pedir explicações sobre como foi em- 
pregado o dinheiro público"). Em segundo lugar, favorecer a colaboração entre os órgãos que fazem a avaliação: evitar que existam feudos, criar um mercado de avaliação, um confronto cooperativo.

Deste modo, sustenta Viveret (1989, p. 58), seria possivel fazer um "bom uso do atraso francês". Enquanto lalecomer, a França poderia aprender com as experiências positivas dos outros paises e superar os próprios limites. Viveret dá alguns exemplos: a importância do papel do Parlamento em promover a avaliação, tanto nos Estados Unidos quanto na RFT (República Federal Alemã), diante do escasso envolvimento do Parlamento francês; o favorecimento dos usuários nas inspeções japonesas, em comparação com a indiferença francesa no assunto; a diferença entre avaliação e controle administrativo que ocorre em todos os países, enquanto na França tende-se ainda a os identificar; a falência das abordagens positivistas e tecnocráticas dos paises há mais tempo envolvidos nestas práticas, enquanto na França eles têm o exemplo recente do favorecimento do relatório Deleau.

Para ViverET, a avaliação serve sobretudo para alimentar o debate democrático e reforçar os contra-poderes. Ele faz, de fato, uma distinção entre a função de avaliar, que é a função política de "atribuir um valor" às ações desenvolvidas, e a função técnica dos especialistas, que é a de facilitar a atribuição de valor. Assim, ele critica tanto as abordagens experimentais da avaliação quanto as políticas de racionalização (como a Rcb) por serem portadoras de uma "visão exclusivamente metodológica", que esquece a "dimensão política" (1989, p. 46). Esta última, ao contrário, viria ajudada pela dimensão do pluralismo, seja no sentido de envolver mais pessoas e mais instituições, seja em colocar à prova os diversos métodos dos pesquisadores.

Esta posição suscita dois tipos diferentes de reação nas figuras institucionais que estamos observando. Insistindo na dimensão politica da avaliação, não se consegue realmente uma abertura nas forças da Administração Pública. Apelando à cooperação e ao confronto pluralista entre as diversas abordagens, obtém-se a simpatia dos especialistas, mas não se entra plenamente no seu debate.

Contemporaneamente, porém, assiste-se a um movimento diferente entre estes últimos (reunidos em centros de pesquisa privados ou universitários, ou em cabinets d'audit privados), ${ }^{12}$ que, nesse meio-tempo, responderam em grande número os appels $d$ 'offre de avaliação das várias entidades públicas. A sólida tradição de estudos organizativos que se tem sobre os ombros (com as diferentes abordagens estratégicas, sistemáticas, etc.), assim como os primeiros estudos de avaliação realizados e as experiências estrangeiras estudadas, levam a uma rápida discussão do modelo experimental e à elaboração de outras abordagens.

Nesta situação, exerce uma grande influência a posição de Eric 
Monnier, diretor do Ceops (Conception d'évaluation pour les organisations et les politiques publiques - junto à École Nationale des Travaux Publics) e autor de um livro que é o único manual sobre esta matéria produzido na França (MonNIER, 1987). Monnier critica o paradigma experimental, porque nele os avaliadores são levados a ser cientistas tout court que perseguem critérios da reprodutibilidade e de validade externa, deixando aos políticos a análise das conseqüências da sua avaliação, contrapondo-lhes o paradigma "endossistêmico", que se baseia em pressupostos alternativos e se inspira na corrente da avaliação qualitativa de autores como Patton Scriven, Cronbach, etc. (cfr. também, DURAN \& MONNIER, 1992, p. 245). Seguindo esse paradigma, dada a complexidade das "máquinas vivas", cada informação deve ser relacionada à complexidade irredutivel do sistema e não pode ser reduzida a um conjunto de observações separadas que tenham validade externa (MONNIER, 1990, p. 135). A avaliação será, portanto, "endoformativa" quanto às suas metas e "pluralista" quanto aos sujeitos: terá de envolver os vários atores de uma política, dos que decidem aos funcionários, aos interessados ou beneficiários, e exigirá um especial savoir-faire dos "encarregados da avaliação" (termo preferido ao de avaliadores) que terão de agir, além de como metodologistas, também como mediadores, sempre próximos das partes em causa, para facilitar as relações recíprocas. De fato - segundo MONNiER (1987, p. 156) - a avaliação "serve para clarificar as situações novas, lutar contra a entropia social, que pode paralisar a vontade mais determinada, e, também, para evitar que os processos iniciados se interrompam bruscamente ou sejam bloqueados por conflitos sem solução". $\mathrm{E}$, prestando atenção à mudança de contex to e às relações que se estabelecem entre os atores no próprio decorrer da ação, esta tende a focalizar um processo de aprendizagem coletiva (MONNIER, 1992, p. 6).

A posição "pluralista" de Monnier e a "democrática" de Viveret coincidem quando ambos rejeitam a idéia de confiar a avaliação a organismos externos de especialistas, e propõem que a avaliação seja confiada a um grupo ad hoc — para quem foi criada a expressão "instância da avaliação" - composto de internos e externos (politicos, usuários e "encarregados da avaliação"). A primeira referência à "instância da avaliação" está presente no Relatório de Viveret (1989, p. 29), do qual trataremos no próximo parágrafo; mas Monnier já havia falado de "avaliações pluralistas" na segunda parte do seu manual. Uma conceituação mais ampla só vai ser feita em 1990, na declaração que MONNIER (1990, p. 124 e seg.) fará em um seminário sobre avaliação organizado pelo Commissariat Général du Plan e pela ENA. Como veremos, receberá uma sanção oficial no I Relatório do Conseil scientifique de l'évaluation. Com isto, porém, estamos em uma outra fase da nossa reconstrução. 
O problema sofre uma aceleração decisiva em direção a uma fase operacional com o Governo Rocard que, assumindo no início de 1988 , indica entre os próprios objetivos "um dever de avaliação das politicas públicas". Rocard, entre outros, provém da Inspection des Finances e pretende valorizar as capacidades do Commissariat Général du Plan. ${ }^{13} \mathrm{O}$ seu governo é, assim, caracterizado pela tentativa de associar setores importantes da Administração Pública à política de modernização do Estado e, nesse sentido, ele associa a avaliação ao conceito chave da responsabilidade, ${ }^{14}$ que deve inspirar o comportamento de toda a função pública. (A circular de 23/2/1989, que fixa os critérios desta ação, diz: "não pode existir autonomia sem responsabilidade, nem responsabilidade sem avaliação").

São duas as novidades importantes desta fase, na introdução da avaliação, como prática generalizada do Estado. A primeira é a instituição cada vez mais freqüente das comissões de avaliação setoriais, que dizem respeito ao funcionamento de organismos (como a universidade, a pesquisa, a saúde) ou à atuação de políticas (como a formação profissional ou a cidade) ou a leis que tenham incorporado um mecanismo de avaliação.

Este último aspecto é particularmente importante. Começa-se, de fato, a aprovar um novo tipo de instrumento legislativo, que se aproxima dos programas americanos. A primeira lei deste tipo é a do revemu minimum d'insertion, ${ }^{15}$ que estabelece que os seus dispositivos de aplicação sejam avaliados após quatro anos. Mecanismos de avaliação semelhantes são previstos também em outras leis, como a sobre o aborto, a lei sobre crédito-educação (n:. 679, de 1990) ou a Loi d'orientation sur la ville (1.91/1991).

A segunda novidade refere-se à criação de um sistema de avaliação central que visa amplificar as iniciativas tomadas e generalizá-las a nivel interministerial: diz respeito ao conjunto das politicas governativas e pretende evidenciar as suas inter-relações. Este desenvolvimento é precedido pelo pedido feito por Rocard a Viveret de preparar, no mês de maio de 1989, algumas propostas para colocar em andamento procedimentos e dispositivos de avaliação das políticas públicas.

Nesta carta de nomeação (22/7/1988), Rocard aponta os motivos que o inspiraram: "integrar a dimensão do meio-termo tanto na ação do Estado quanto no debate e na intervenção da sociedade política c civil" (isto significa ter em conta o conhecimento dos processos de implementation e das estratégias dos atores); "modernizar os instrumentos da inteligência política" da França (é o seu modo de definir a reforma do Estado). Ele sugere, assim, a Viveret trabalhar junto aos "responsáveis pela administração, que refletiram sobre o tema da avaliação, assim como 
junto aos laboratórios de pesquisa e aos atores da sociedade civil e política, em particular o Parlamento, cuja participação é indispensável ao sucesso deste projeto" (o apelo ao Parlamento tem o sentido da constatação de escasso envolvimento e de um augúrio mas, como veremos em seguida, não será entendido no sentido taxativo).

Daqui nasce o Relatório Viveret (1989), que é centrado em dois temas-objetivo da democracia (transparência e pluralismo) e na eficácia. Ele contém uma síntese das experiências de avaliação, sobretudo as dos Estados Unidos e dos primeiros passos franceses; retornando à oposição entre "interesse metodológico" e "interesse político". Faz, depois, o resumo da situação institucional existente e propõe, enfim, um conjunto articulado de organismos.

Em particular, o Relatório prevê a realização de um mercado de avaliação. A organização pluralista da demanda deveria compreender tanto um pólo governativo (Conseil interministeriel de l'évaluation) quanto um pólo público independente (Conseil national de l'évaluation, que seria chefiado pelo Parlamento e outros órgãos como a Cour des comptes), que teriam a possibilidade de utilizar o auxílio de dois organismos comuns (o Conseil scientifique de l'évaluation, composto por especialistas, e o Fond national de l'évaluation, para a gestão financeira). Quanto à oferta pluralista de avaliação, esta deveria provir da administração, dos órgãos de jurisdição administrativa, do Parlamento, e do próprio Cse, além de outras entidades públicas independentes e, naturalmente, dos centros de pesquisa acadêmicos e privados.

Poucos meses depois, em 22/1/1990, é publicado um decreto sobre a avaliação (no. 90/82), que contempla grande parte dos instrumentos previstos no Relatório Viveret, com a exclusão significativa do pólo independente da demanda. Depois de ter defïnido o objetivo da avaliação de uma política pública, de um modo ainda um pouco nebuloso ("Pesquisar se os meios jurídicos, administrativos ou financeiros colocados em funcionamento permitem produzir os efeitos esperados por esta política e atingir os objetivos para os quais são destinados, Art. 1"), e depois de ter limitado o alcance da publicidade da avaliação, estabelecendo que podem the ser submetidos todos os campos da atividade administrativa, salvo os de caráter secreto (Art. 2), o decreto individualiza os organismos submetidos à avaliação e os seus objetivos especificos.

São, assim, instituídos três novos organismos:

- O Comité interministeriel de l'évaluation (Cime), que é formado pelos representantes dos seis ministérios mais envolvidos (finanças, orçamento, reformas administrativas, etc.). Ele é encarregado de "desenvolver e coordenar as iniciativas governamentais em matéria de avaliação das políticas públicas", tendo em conta que tais iniciativas podem vir de um ou mais ministérios, ou ainda, de outros organismos como o Conseil 
d'État, o Cour des comptes e o Médiateur de la République (e não, notese, do Parlamento - um problema que voltaremos a discutir), e que as iniciativas deverão ser apresentadas sob forma de projetos de avaliação, que indiquem a modalidade de atuação e a escolha dos operadores públicos ou privados encarregados de proceder à avaliação (Art. 2, c. 4);

- O Fond national de l'évaluation (Fnde), cujos créditos são inscritos no orçamento do Primeiro-Ministro e geridos pelo Commissariat Général du Plan; e

- O Conseil scientifique de l'évaluation (Cse), que é o órgão de caráter científico encarregado de "favorecer o desenvolvimento dos métodos de avaliação", de "definir uma deontologia na matéria" e de "assegurar a qualidade e a objetividade dos trabalhos que usufruem dos fundos do Fnde" (Art. 8, c.1). Ao Cse é também atribuido um objetivo, não muito preciso, de "formação de especialistas" e de desenvolvimento (Art. 9).

O acordo que o Governo encontrou, do qual o Presidente Mitterand foi o mediador, baseia-se nos seguintes pontos. Em primeiro lugar, sendo o Cime o principal constituinte das avaliações, insistiu-se no tema da avaliação como instrumento para uma coordenação das atividades dos diversos ministérios. De fato, freqüentemente, os efeitos não previstos de uma medida ministerial são sempre aqueles que são também da competência de outros ministérios e é necessário abolir estas barreiras de competência e conhecimento. O presidente do Commissarial Général du Plan, DE Foucauld (1992, p. 20), disse, a propósito, que "procura-se levar em consideração as políticas cujas colocações são de caráter humano, social e financeiro ao mesmo tempo".

Em segundo lugar, è atribuido um papel importante ao Commissariat Général du Plan. Ele desenvolve uma atividade de elaboração e de coligação, como secretário do Cime, e assegura a comunicação entre o Cime e o Cse (este último, sobre o qual falaremos depois, funciona no mesmo local). Entretanto, o Commissariat administra o Fnde e a quota de financiamento das avaliações a cargo do Cime (trata-se de $50 \%$ do custo: os outros $50 \%$ ficam a cargo dos ministérios ou dos órgãos que pediram a avaliação).

Em terceiro lugar, constituindo só o Cime, e não o Cne, o Executivo não teve a preocupação de "garantir-se, sozinho, as condições da avaliação da própria execução" - como insinua em tom de brincadeira o Cse (1992, p. 19). Trata-se de um velho problema levantado várias vezes durante os debates que precederam as escolhas governativas: temia-se, de fato, que "o Executivo, sob a aparência de avaliar e de se fazer avaliar, [desempenhasse] todos os papéis" (FRAISSE, 1988, p. 61). Esta particularidade, bem francesa, não deve porém ser julgada a priori. Se pode ser verdade - como escreveu o Conseil économique et social 
$(1991)^{16}$ - que assim se expresse "uma dúvida sobre a capacidade do movimento de avaliação de se afastar efetivamente de uma certa tutela por parte do Executivo", é ainda mais verdadeiro que um impulso do alto como o vindo da Presidência da República e do Primeiro-Ministro, tenha condições de envolver outros organismos ainda hesitantes (além de construir uma extraordinária medida de auto-reforma).

O problema diz respeito sobretudo ao relacionamento com o Parlamento. Este não havia dado sinais positivos na matéria. Existia, desde 1984, um organismo de avaliação ex ante (Oects, Office parlamentaire d'évaluation des choix technologiques et scientifiques), que, porém, não era muito ativo. ${ }^{17}$ Não haviam sido apresentadas iniciativas parlamentares de avaliação ex post (uma estatística apresentada no Relatório Viveret mostrava que o Parlamento tinha comissionado $0,5 \%$ !). O substancial desinteresse dos deputados levou à idéia de que eles - também em virtude da reforma da descentralização - dessem mais ouvidos aos políticos locais do que aos políticos nacionais, e que, no relacionamento com o seu público, fossem penalizados por se preocuparem com o orçamento e outros negócios gerais.

Todavia, depois do decreto de 22/01/90, as coisas mudaram também devido ao impulso dado pelo presidente da Assembléia Nacional, Laurent Fabius. A Assembléia tomou duas iniciativas, que indicam a sua boa vontade em dar instrumentos de controle da atuação das leis por ela lançadas (Conseil économique et social, 1991, p. 38). A primeira trata do "controle dos regulamentos de aplicação das leis", para evitar as deformações do espírito das leis nessa fase legislativa ulterior. A segunda trata da criação de "missões de informação temporâneas sob condições de aplicação de uma legislação". Estas missões podem ser comuns a mais comissões permanentes. Está previsto que a cada ano sejam postas em ação duas ou três e que durem seis meses. Em 1990, foram criadas missões sobre a legislação urbanista e sobre moradia e bioética.

Em conclusão, com o decreto de 1990 , não se quis criar um sistema importante para reorganizar toda a administração - como estava potencialmente previsto no Relatório Viveret. ${ }^{18}$ Todavia, as mudanças previstas são bastante grandes para influenciar o comportamento de muitos órgãos. Em pouco tempo todos (muitos, segundo uma opinião que circula em ambientes of iciais) concordarão com a avaliação. Quem era favorável, começou rapidamente a trabalhar, como a Inspection des finances, que fez da avaliação um instrumento da própria modernização. Quem tinha dúvidas, como a Cour des comptes, começou a rever alguns dos próprios comportamentos em matéria, por exemplo, de publicidade. E os órgãos aos quais foi oferecida a possibilidade de utilizar os serviços do Cse, como o Médiateur ou o Conseil économique et social, não deixaram escapar a oportunidade. 


\section{O aparelho institucional em ação: o mecanismo Cime-Cse}

Com dois anos de distância, dispomos de dois relatórios do Cse que, além de prestar contas da própria atividade, difundem - como estava preestabelecido - as experiências existentes e fornecem elementos sobre a qualidade da avaliação.

"O Cse — diz o Art.1 do decreto 90/470 de 7/6/1990 — é composto de onze personalidades nomeadas por decreto pelo Presidente da República e escolhidas em virtude da competência em matéria de avaliação ou no campo das ciências econômicas, sociais e administrativas."19 O orçamento do Cse prevê somente quatro postos de trabalho: dois dirigentes (rapporteur général, rapporteur général adjoint) e duas secretárias. As atividades do Cse podem estar entre as que incidem diretamente sobre as avaliações singulares propostas pelo Cime e financiadas pelo Fnde (para as quais são previstos os pareceres iniciais e finais), e aquelas que sustentam a atividade da avaliação em geral: documentação sobre sistemas de avaliação estrangeiras, pesquisa e formação. No que diz respeito à formação, o Cse somente pode participar das iniciativas em comum acordo com outras administrações e introduzir a avaliação nos cursos das universidades e nas Grandes écoles. ${ }^{20}$

O I Relatório (Cse, 1992) tem um título que parece dizer mais respeito ao encerramento da fase preparatória do que aos novos desenvolvimentos: "A avaliação: da especialidade à responsabilidade". Ele se refere ao primeiro ano de atividade no qual, tardando a vir o impulso dos projetos de avaliação do Cime, o Cse dedicou-se a recolher dados do que existia em todas as administrações e lançar as bases para um trabalho futuro. O II Relatório (Cse, 1993) tem por título $A$ avaliação em desenvolvimento e testemunha, outrossim, o avanço impetuoso que veio logo em seguida àqueles primeiros passos, seja como atividade do Cse, seja como influência do seu trabalho (isso se refere tanto às politicas submetidas à avaliação quanto ao envolvimento de novas administrações descentralizadas, sobretudo as regionais - cfr. Cse, 1993, pp. 91-120 e 8790). São documentos de trabalho, cheios de informações e de reflexões in progress, que introduzem um novo estilo na literatura da Administração Pública francesa. A leitura conjunta dos dois relatórios permite reflexões interessantes sobre o modo pelo qual o trabalho de avaliação pode funcionar como instrumento de reforma do Estado.

O que mais nos surpreende no I Relatório - sobretudo se temos em mente a história contada até aqui - é o imponente inventário das instituições e serviços competentes em matéria de avaliação: cerca de vinte e quatro, das mais gerais, como a Assembléia Nacional, às mais setoriais, como a pesquisa, as universidades, a formação profíssional e as de Minis- 
tros (indústria, agricultura), e de programas individuais (o Rmi). A impressão que se tem, entretanto, é que há uma difusão generalizada da avaliação, o que é, na realidade, mais uma ampliação das missões de inspeção e controle existentes em cada um desses organismos do que uma nova visão capaz de sugerir uma efetiva reorientação.

Vejamos, então, como funciona o mecanismo interministerial de demanda de avaliação. Ele é acionado pela escolha, por parte do Cime, dos temas apresentados pelas várias administrações e pela sucessiva apresentação de projetos de avaliação por parte do Commissariat Général du Plan, que age como secretariado do Cime (Cse, 1992, p. 69). O projeto de avaliação indica qual é a política a ser avaliada e qual a finalidade a que se propõe, em vista de que possiveis reformas. Esta é uma passagem bastante delicada. De fato, o Cime e o Commissariat Général du Plan tiveram em todo o processo um grande peso (que se discute pouco) e que deriva do modo pelo qual vem formulada a demanda de avaliação: a construção do objeto de análise. Só Monnier acena diretamente ao "insuficiente profissionalismo" (...) dos envolvidos que, na maioria das vezes, são incapazes de formular um pedido de avaliação claro que explicite a lógica de ação e a problemática de avaliação" (1992, pp. 161-62). Monnier lamenta, sobretudo, a discrepância entre um mecanismo de avaliação, inspirado no pluralism ) (institucional e metodológico), e o fato de que "a maior parte dos projetos adotados pelo Cime são redutiveis, sem dúvida, ao paradigma 'gerencial' " (1992, p. 160), e atribui esta preferência a uma maior afinidade e percepção dos funcionários das administrações envolvidas. Agora, mesmo que isso não seja sempre verdade, ${ }^{21}$ poderíamos propor que o Cse intervisse também nesta fase, apesar de ser mais politica e menos metodológica.

Os primeiros "projetos de avaliação" lançados com esses procedimentos, em 1990, foram os cinco seguintes: 1) sobre politica de inserção dos adolescentes em dificuldades: propõe acompanhar os adolescentes por váriòs anos, e terá, portanto, uma certa duração (diz respeito aos Ministérios da Justiça e dos Assuntos Sociais); 2) sobre a reabilitação de casas populares, particularmente as construções já existentes, para verificar se é melhor reformá-las, demoli-las, etc. (a cargo dos Ministérios da Habitação, Finanças e da coletividade local); 3) sobre um programa de reorganização do currículo escolar (a cargo dos Ministérios da Cultura, Juventude e Esportes, Educação e da coletividade local); 4) sobre o acesso da população mais carente aos serviços públicos; 5) sobre o impacto da informática na administração.

Em 1991, os projetos de avaliação foram sete. Três propostos pelo Cime: sobre a política da luta contra as drogas e a toxicodependência; sobre a administração das zonas úmidas; sobre segurança nas estradas. Quatro foram propostos pelo Conseil économique et social: sobre "polí- 
tica de ajuda na localização das atividades nas zonas de conversão"; sobre "eficácia econômica e social de ajuda aos aluguéis"; sobre "politica de luta contra a miséria"; e sobre "intervenções do Estado a favor dos assalariados com mais de 55 anos" (Cse, 1993, pp. 20-23).

Como observa o relator geral do Cse, Perret, Bernard (1993, p. 74), por mais importantes que sejam os argumentos objeto destas demandas de avaliação, eles não são prioritários — sobretudo do ponto de vista do orçamento estatal. Outros fatores desempenham, portanto, um papel na decisão de pedir uma avaliação. Perret faz uma lista significativa: em primeiro lugar, estão os problemas de identidade e de legitimidade de administrações frágeis, que querem redefinir os termos da sua colaboração com outros mais fortes (é o caso dos adolescentes em dificuldades, da toxicodependência e da segurança nas estradas).

Em segundo lugar - o que vai no sentido da inversão da ordem da qual falamos no inicio - pede-se uma avaliação para reformular os objetivos considerados pouco claros, como no caso do recebimento das pessoas prejudicadas nos serviços públicos (uma politica que não existia como tal antes que se decidisse avaliá-la) ou nos da luta contra a pobreza; ou, então, para dar importância a projetos que não gozam de uma forte sustentação, como no caso da informática na administração, que, mesmo sendo objeto de velhas diretrizes, não constituía uma prioridade do Governo. Trata-se, portanto, de administrações que souberam entender um novo desafio representado pela avaliação e decidiram ser responsáveis e participar.

Por último - diz Perret - vêm os casos nos quais canonicamente existe a preocupação com a eficácia de uma política (é o caso da política de reabilitação das casas populares).

Estes fatores constituem motivações que o Cse deve ter em conta no desenvolvimento do próprio trabalho. Como vimos, o decreto atribui a ele a tarefa de "desenvolver os métodos de avaliação e definir uma deontologia na matéria" (Art. 8). O Cse não faz auto-avaliações 22 e nem mesmo elabora as próprias metodologias. Ele, aliás, diz que cada caso particular requer métodos e análises diferentes.

Encontramo-nos frente a uma interpretação do próprio papel do Cse, depois de ter sido feito um cuidadoso balanço da situação da avaliação na França. A sua primeira constatação foi que, apesar de na França existirem tantos centros de pesquisa e instituições, ${ }^{23}$ não existia - ao contrário dos países nos quais a avaliação nasceu e tem uma sólida tradição - uma profissão de avaliação identificada por métodos, paradigmas de conhecimento e associações profissionais. Mas teria sido fantasia querer fazer nascer de imediato uma tal corporação (cautela também quanto aos objetivos de formação) e impor do exterior e do alto os critérios de uniformidade. Entretanto, esperava-se que aquele pluralismo fos- 
se uma vantagem da situação francesa que não podia ser desprezada: "A inclusão de práticas diferenciadas e heterogêneas - escreveu Monnier (1992, p.161), que nessa altura se transformou em membro do Cse fazem dela um sistema aberto e suscetivel de evolução e adaptação". Por todas estas razões, era muito mais sábio limitar-se a procurar criar sinergia entre as diversas realidades, individualizando algumas simples orientações que pudessem permitir um acúmulo de experiência e uma troca entre todos os que se empenharam no campo da avaliação.

Mais ainda, o mesmo modelo institucional seguido — da instância de avaliação que, veremos mais à frente, associa internos e externos e propõe modificações na atividade do Governo - comporta a colaboração de pessoas de diferentes proveniências institucionais, diferentes competências e diferentes interesses. Trata-se, portanto, de encontrar um modus operandi que favoreça um processo interativo de conhecimento coletivo e que sirva para melhorar a política.

Isto é o que o Cse chama "qualidade da avaliação". Depois de ter escrito na abertura do II Relatório (Cse, 1993, pp. 6-11) que a escolha das cinco famosas perguntas fosse deixada a cargo de quem fará a avaliação - além de depender do caráter da política que é avaliada e das indicações do projeto de avaliação - o Cse mantém o seu objetivo de indicar três diretrizes que dizem respeito aos métodos de análise, à deontologia e à utilidade da avaliação. Para cada uma delas procura a possibilidade do encontro entre o pluralismo dos sujeitos e métodos, de um lado, e a universalidade das aplicações e dos destinatários, de outro (Cse, 1993, pp. 122-129).

Observando mais de perto, começaremos pelos métodos. Aqui vêm individualizados vários critérios. Se as abordagens são as mais variadas, convém que elas sejam explicitadas ("transparência dos métodos"). Devem ser escolhidas amostras representativas de uma população ou casos que se prestem a comparações com outras situações e outros contextos ("possibilidade de generalização", seja com métodos estatísticos ou comparativo-analógicos). As teorias devem ser levadas a uma lógica casual (que, note-se, "pode ir da análise das correlações entre o que é possivel medir à interpretação de processos e ações e à explicitação dos sistemas") (Cse, 1993, p. 11) e devem excluir os sistemas de recolhimento de dados viciados em pressupostos metodológicos (confiabilidade). Os resultados não devem ser influenciados pelas preferências ou pelas posições institucionais dos responsáveis pela avaliação (objetividade). São principios evidentes, algumas vezes expressos com uma terminologia um pouco científica, outras vezes com grande visão. Nenhum método deve ser excluido por princípio, todos devem justificar - ou pelo menos, tornar explicitas - as próprias escolhas, através dos resultados do próprio trabalho. 24 
Por outro lado, se pensamos que na instância não existem apenas as metodologias mas também - como veremos - pessoas interessadas, por várias razões, na política de avaliação, estas sugestões servem também para facilitar o relacionamento entre os pesquisadores e outros membros da instância, evitando que os primeiros usem de modo arrogante a sua competência em relação aos outros.

No que diz respeito à deontologia, não nos referimos a um princípio abstrato de separação entre políticos, administradores e técnicos (ou entre os que decidem, implementadores e avaliadores), se bem que, no caso concreto de um órgão composto, que pelo fato de ter como objetivo um melhoramento da política, não se deve esquecer de se estar sempre desenvolvendo uma atividade de caráter cognoscitivo, enquanto se espera que outros dêem andamento às propostas que pareçam mais convincentes (Cse, 1993, p. 7).

A terceira diretriz deste programa é a da utilização. As avaliações — diz-se — devem ser "pertinentes", devem ser cumpridas em um periodo breve que permita ter em consideração o processo de decisão em curso (na informática levou dois anos e meio, o que foi considerado muito tempo). Por outro lado, devem fornecer informações "compreensíveis e úteis": no segundo parecer sobre a informática, por exemplo, lamenta-se que a avaliação seja muito tímida nas propostas, como pouco "prospectiva", sobretudo, em relação às vantagens financeiras e, em geral, sobre como a informática poderia ajudar nas decisões.

$\mathrm{O}$ último ponto, note-se, não se refere somente aos que decidem, mas abrange também o público e vem de encontro àquela exigência de transparência que - segundo VIVERET (1989) - era uma característica que a avaliação poderia trazer à democracia. "As reflexões produzidas pela avaliação — diz o II Relatório (Cse, 1993, p. 127) — podem (...) contribuir na formação do julgamento da opinião pública sobre a política avaliada e a sua informação sobre problemas sociais ligados à politica."

É baseado nesses critérios que o Cse dá um primiro parecer sobre o projeto de avaliação e um segundo sobre o realizado na instância de avaliação que trabalhou com base naquelas indicações. Não se trata de meta-avaliações (a avaliação das avaliações), mas somente de uma contribuição ao aprimoramento da qualidade da avaliação, que significa profundidade no conhecimento dos fenômenos e capacidade de proposta de reforma.

\section{A instância da avaliação}

Para cada avaliação forma-se uma instância de avaliação composta de dez a quinze pessoas - cujo número e identidade depende da avaliação 
a fazer - interessadas nas políticas objeto da avaliação. LAMArQue, Danièle (1993, p. 80) identifica várias categorias - internas à administração ou externas (como políticos, usuários, associações) —, com base nos conhecimentos que trazem. Para alguns, essa coligação é óbvia, como nos casos dos representantes dos setores avaliados, dos membros das instituições de coligação entre administração e usuários, e dos especialistas das disciplinas interessadas. Menos óbvio é para os membros dos corpos de inspeção, chamados "pelo seu conhecimento dos modos de funcionamento e das técnicas de análise do setor administrativo", e para os "responsáveis pelo setor privado que atuem em campos comparáveis àqueles que são objeto de avaliação", que vêm inseridos "pela sua capacidade de relativizar as observações feitas a propósito das políticas públicas" (temos, aqui, um modo prático de fazer a comparação entre análises de qualidade no setor privado ou público, que deu origem ao debate sobre a avaliação).

É evidente que a instância de avaliação não deve ter uma exigência de representatividade total, coisa que - dada à complexidade e transversabilidade das políticas em questão - seria impraticável. A preocupação, ao contrário, é de que ela seja eficaz e possa trabalhar bem (sobre este aspecto da questão, o Cse também pode se expressar).

A clara opção pela participação dos internos - que deverão vir de mais de um ministério - justifica-se pela necessidade de utilizar sua competência, sem porém serem condicionados pelo modo de colocar as questões da administração. De outro lado, este novo organismo, do qual também os internos fazem parte, é autônomo nas respectivas administrações e deve se comportar com imparcialidade e objetividade.

Quanto à presença dos externos, ao contrário, deve envolver todos os pontos de vista "legítimos", ou seja, aqueles dos usuários, políticos, associações e pessoas interessadas naquela política, mas que não são representantes de um público genérico, ou de um não melhor definido interesse geral.

Em particular, a questão da participação dos usuários foi muito debatida. ${ }^{25}$ É dificil que eles participem diretamente, e o tipo de representação que se pode obter através das associações de consumidores, o Médiateur de la République, ou os políticos eleitos por eles, raramente é satisfatório. São as administrações com mais contato com os usuários, como os correios ou a polícia - segundo Sylvie Trosa, rapporteur adjoint do $\mathrm{Cse}^{26}$ - aquelas que mais sentiram a necessidade da avaliação e dela fizeram melhor uso.

Uma vez constituido e recebido o projeto de avaliação, a instância determina a metodologia que virá a seguir, os meios de utilização, estabelece as tarefas e escolhe os "encarregados da avaliação", entre eles os que fizeram a própria oferta (o Cse pode ainda dar um parecer sobre 
quem é mais apto para conduzir estas análises). Enfïm, a instância de avaliação dirige e coordena os trabalhos das várias equipes de pesquisa e formula as recomendações feitas pelo Cime.

A instância da avaliação - mantém-se - é o maîre d'ouvrage, em todos os aspectos da avaliação, até mesmo naqueles de qualidade e metodologias, mesmo se nem todos os seus membros sejam metodológicos. Isto significa que não há um conhecimento privilegiado (aquele de um pressuposto avaliador), mas um trabalho coletivo, no qual convergem os mais diversos conhecimentos. Por sua vez, isso permite redefinir o papel dos encarregados da avaliação que, além das próprias competências, terão de compreender a complexidade dos jogos dos atores, e agir como "facilitadores", "animadores do debate", etc. (Cse, 1993, p. 76).

A instância de avaliação transforma-se, assim, em uma instância de pluralismo enquanto local de debate e procura de consenso. Trata-se de um processo de conhecimento, no qual "a vivência coletiva de um grupo cujos membros são constantemente levados a enriquecer os seus conhecimentos e colocar em causa os fundamentos" (LAMARQUE, 1993, p. 81), é possivel recriar novas sínteses entre competência e independência. E, depois, associando encarregados da avaliação, funcionários e público, pode-se criar um ambiente mais favorável a aceitar e fazer aceitar os resultados da avaliação.

Existe, em conclusão, uma diferença exata de funções e papéis. $O$ Cse dá um parecer inicial e final sobre os métodos seguidos; a instância de avaliação desenvolve a avaliação e formula as recomendações. Sobre este relatório de avaliação, o Cse dá o seu segundo parecer, que é enviado - além da própria instância - ao Commissariat Général du Plan, para que o mesmo chegue ao Cime, de modo que o Governo possa tomar decisões para as modificações que colocará em prática.

Uma última questão importante diz respeito à publicação dos relatórios. O problema não é a sua divulgação, que é assegurada pela Documentation française, mas a pouca divulgação que eles têm nos jornais e, por conseqüência, na opinião pública (VIVERET, 1992): nada comparável ao canal de televisão especializado, que existe nos Estados Unidos, e à influência da avaliação do Gao (General Accounting Office) sobre o debate político naquele país. Mais uma vez, estamos diante de um problema cultural da avaliação, que só pode ser enfrentado a partir das experiências concretas que se fazem e da capacidade em falar a um público mais amplo.

\section{Existe um modelo francês de avaliação?}

É talvez legítimo, nesta altura, dar uma resposta a um ponto que 
pode ter surgido na mente de algum leitor: isso de que falamos deve ser considerado como modelo francês de avaliação?

Antes de responder a esta pergunta, devemos fazer duas considerações. A primeira é uma nota de cautela: apresentamos — é verdade — um mecanismo que permite a vários atores aprender a arte do ajustamento e da reformulação de uma politica, mas não estamos em condições de dar um parecer sobre a ajuda que a avaliação tenha, efetivamente, dado à decisão (não existe ainda um acompanhamento administrativo ou legislativo às primeiras avaliações). Talvez seja melhor não esperar tanto. DE FouCAULD (1992, p. 19) diz que o mérito principal do mecanismo é o de existir, e que não é garantido que "o grande interesse pela avaliação seria o mesmo, se as autoridades que o quiseram tirassem as conseqüencias que the dizem respeito do seu desejo de fazer com que desempenhem um papel importante para modernizar o Estado e ativar o debate democrático".

A segunda consideração, ao contrário, acrescenta uma nota de otimismo. A avaliação mostrou a sua capacidade de ser uma medida bipartisan, que favorece o diálogo: foi promovida na época da primeira coabitação, foi instituída por um governo socialista e sobreviveu à mudança de governo, com as eleições de março de 1993.

Se quisermos responder à pergunta sobre a existência de um modelo francês, podemos seguir Perret que procura oferecer uma resposta através de uma análise comparada dos sistemas de avaliação. Segundo Perret, não se pode falar de um verdadeiro modelo francês, contraposto ao modelo dominante a nivel internacional, de origens anglo-saxônicas (PERrit, 1993, p. 61), sobretudo por causa da diversidade dos métodos e estruturas que vimos caracterizar o panorama da avaliação na França. Existem, porém, as tendências próprias à situação francesa, seja nos procedimentos (o mecanismo Cime-Cse e a instância da avaliação), seja na utilização social que vem sendo feita da avaliação. Aqui, a divergência é brutal, sobretudo em comparação com o mais conhecido modelo europeu de avaliação, que é o inglês.

Isso nos leva ao tema dos remédios para a crise do Estado da qual partimos. No sistema inglês, a avaliação é de competência do Ministério do Orçamento e a Administração Pública é organizada com base em um princípio de responsabilidade individual - nos termos de uma "capacidade de prestar contas" (accoumuability) - do dirigente do serviço em relação ao poder político. A avaliação vem assim entendida como um modo de estabilizar o rendimento da despesa: value for money, com base em uma análise da relação entre objetivos (quantificáveis e monetarizáveis) e meios (financeiros). De outra parte, não existem instituições que se dediquem à avaliação, nem tampouco a avaliação consiste em uma pesquisa feita por externos e financiada por um percentual do orçamento do programa em questão. 
Na França, ao contrário, a responsabilidade da administração é concebida em termos mais amplos. Em primeiro lugar, como já vimos, o objetivo é o envolvimento do conjunto dos funcionários (e não somente dos dirigentes, os diretores públicos), e os que são considerados como atores a part entière da evolução que o Estado deve experimentar, para responder melhor às necessidades da sociedade (diz PERRET, 1993, p. 73). Temos, ainda, como ponto de referência, a sociedade na sua complexidade, as estratégias dos atores e as diversas lógicas de ação que se colocam em movimento com os programas sociais. Segundo PERRET (1993, p. 67), pode-se dizer que na França "a dupla ator/problema tem um papel mais decisivo no processo de reforma e reformulação das políticas do que a dupla objetivos/meios".

Esta contraposição não significa, porém, que com a avaliação se procure só a democracia deixando de lado a eficiência das intervenções do Estado - ambos são objetivos indicados no decreto governativo, que todo o sistema leva em conta nos seus pareceres. É verdade que o equilibrio entre os dois aspectos vem sendo perseguido através dos métodos pluralistas. Nos conselhos do Cse e no funcionamento da instância, vimos em ação uma forma de fazer emergir soluções a problemas reais e sentidos, através de um debate que permite aos vários atores se compreenderem reciprocamente e encontrar pontos de encontro. É uma ajuda na reforma do Estado e um avanço democrático. ${ }^{27}$ Isso tudo - é de se esperar - não deveria permanecer um atributo tão-somente da situação francesa. 
I Isto incidirá, veremos depois, sobre a institucionalização da avaliação, que não é ligada ao orçamento como na Grã-Bretanha, mas, cm geral, na obra do Governo (cfr. il par. conclusivo).

2 Ver MAZEY (1991). Para uma avaliação dos resultados do primeiro decênio de descentralização, ver Grémion (1992).

${ }^{3}$ A produção de efcitos opostos àqueles descjados (e por isso "perversos") é uma crítica freqüente aos programas de Welfare State, $\mathrm{e}$ influenciou muitos pesquisadores dos programas da War on Poverty americana. Na França, o argumento foi usado particularmente por Boudon, Raymond (1977) na sua análise da escola de massa. Entretanto (STAME, 1990), sustentou que tais teses não permitem à avaliação desempenhar o seu papel no processo decisivo e explorou as oportunidades oferecidas por outras abordagens de caráter interativo. Toda a problemática recebeu recentemente um novo impulso com o trabalho de HiRSCirman, Albert (1991) sobre as Retóricas da Intransigência, um texto que suscitou o desapontamento de BOUDON (1992) e uma resposta de HIRSCIIMAN (1992).

4 Para coordenar a politica urbana nos diversos ministérios, foi instituida a Délégation interministerielle de la ville (Div) $\mathrm{cm}$ cujo interior foi constituido o Comité d'évaluaiion de la politique de la ville.

5 Para esta evolução foi reconhecido o papel de precursor do Centre de sociologie des organizations, fundado por Michıl Crozier nos anos 60. Poderiamos recordar também um texto de titulo explicito, L'état au concret de PADIOLEAU, Jean G. (1982).

${ }^{6}$ Este colóquio aconteceu em Paris, em março de 1991.

7 Ver Nioche \& Polnsard (1985), que contém as atas da convenção L'évaluation des politiques publiques tendo $\mathrm{cm} 1983$ a cargo do Ministére de l'économie e de algumas Grandes écoles; Fondation du futur, 1988, que contém as atas da convenção Comment reformer l'état?. realizada na Assemblée nationale cm 1988; Commissariat Général du Plan (1990), que contém as atas de um seminário organizado junto à ENA cm 1991. Muitos dados contidos depois em Delenu (1986) c sobretudo Crozier (1989): cste último é um amplo relatório sobre os Estados Unidos, Japão e Suécia, fornecido a Crozier pelo ministro da Fonction publique et du plan, Hervé de Charette. Uma ágil documentação contida cm MONNier (1989).

8 "Quando?" distingue entre retrospectiva, concomitante ou prospectiva; "onde?" distingue o nivel no qual se desenvolve, se local ou central; "por quê?" especifica o objetivo, se aumentar a cficiência, cstabelecer indicadores de qualidade ou facilitar a integração; "para quem?" especifica os sujeitos a quen se refere, se são protagonistas dos programas ou o público; "o quê?" especifica se aquilo que aconteceu foi de acordo com os resultados esperados, se o procedimento colocado $\mathrm{cm}$ ação produziu o que verdadeiramente se esperava ou quais são todos os resultados possíveis de uma ação (cfr. Cse, 1993, pp. 6-11). Tendo presente estas perguntas, BonetTl el al. (1987) distinguem entre comparativa, analitica e dinâmica (com relação às funções); enquanto Monnier retoma a distinção de Scriven entre endoformativa c recapitulativa (com relação aos destinatários). MONNIER (1987, p.135) retoma o esquema de Patton sobre as op̧̧òes metodológicas, que cruzam as caracteristicas no contexto de avaliação com os possiveis métodos de análise.

${ }^{9}$ GuBA e LinCOLN identificaram quatro gerações de avaliação que se sucederam nos Estados Unidos: "técnica", nos anos do New Deal, "descritiva", dos anos da guerra até a metade dos anos 60; que dá julgamentos (judgement), entre 1967 e a metade dos anos 70, ou seja, no auge dos programas da Great Society; "reativa" (response), nos anos 
do "reaganismo" (Reagan, presidente dos Estados Unidos.) Cada geração se caracteriza por um objetivo especifíco de avaliação, modelo científico $\mathrm{e}$ o papel do avaliador.

10 Eleanor Chelimsky participou diretamente de algumas convençōes: cfr. CHELIMSKY, 1988 e 1992. A General Accounting Office nasceu como Tribunal de Contas e depois desenvolveu una seção de avaliação, o Program Evaluation Methodology Division. Esta é composta por pesquisadores internos e se vale também de pesquisadores especialistas externos; desenvolve avaliações para qualquer grupo de deputados. $\mathrm{O}$ governo tem um órgão próprio de avaliação, o Office of Management and Budget (OMB).

11 Esta definição ć dada por Monnier (1992) e por Duran \& Monnier (1992).

12 Entre tuntos centros de pesquisas que desenvolveram análises de avaliação, podemos citar o Centre de sociologie des organisations, o Groupe pour l'analyse des politiques, o Centre de sociologie de l'innovation, o Centre d'études de l'emploi.

13 O Commissariat Général du Plan é um Departamento da Presidência do Conselho. Depois de ter desempenhado um papel importante nos anos de planejamento, tem uma particular competência para a análise de médio termo. Ele desempenhou um papel de protagonista no campo da avaliação, tendo realizado os primeiros trabalhos de avaliação, como sobre políticas sociais transversais, sobre o desenvolvimento social nos bairros, sobre dispositivos de inserção. O seu presidente, DE FouCaUld, Jean Baptiste disse recentemente (1992, p. 23) que: "O Plano não é mais um instrumento do Estado; é um lugar onde se reflete sobre o Estado, c nós nos desejamos, nesta perspectiva, que a avaliação se desenvolva tanto no plano quantitativo quanto no plano qualitativo, porque as duas coisas devem ser ligadas (...) (a avaliação) se transformou $\mathrm{cm}$ um ponto de força da nossa ação no quadro de renovação que entendemos induzir na renovação da planificação". Nesse sentido, podemos ver no seminário intitulado Modernisation de l'Étal, no qual vem sendo regularmente apresentadas experiências de reforma no serviço público e de avaliação, que são discutidas à luz da relação entre ef iciência e justiça social. O Commissariat organizou duas convenções, uma cm 1991 c a outra no ano seguinte, sobre os temas da justiça social e da desigualdade, das quais participaram estudiosos de vários países.

14 O X Plano, no qual o relatório foi escrito por François de Closets em 1989, e se intitula Le pari de la responsabilité.

15 A lei sobre Revenu minimum d'insertion (Rmi: o salário mínimo - no. $1088 \mathrm{de}$ 1/12/1988) instituiu uma Comission nationale d'évaluation, presidida por Pierre Vanlerenberghe, que foi empossado $\mathrm{cm} 1989$. Ela se ocupou inicialmente do monitoramento da lei, c fez pesquisas sobre a pobreza c sobre as condições de inserção no trabalho de utilidade social e nas empresas (cfr. VIVERET, 1989). Em 1992, publicou um relatório de avaliação $R m i$ - Le pari de l'insertion, que contém sugestôes em matéria de inserçĩo c "acompanhamento social", c propõe que o Cime faça uma nova avaliação depois de três anos.

16 O Conseil économique et social $\dot{c}$ um órgão consultor composto de representantes dos partidos, sindicatos, empresários, entidades profissionais, etc., análogo ao Cnel italiano. Ele se empenhou muito na avaliaçào, como testemunha o relatório aqui citado e a organização da Première conférence nationale de l'évaluation juntamente ao Observatoire de la décision publique (Ces c Odp, 1992).

17 O Oects realizou cinco estudos sobre: chuvas ácidas, liçōes sobre o incidente em Chernobyl, Aids, semicondutores e TV de alta definição.

18 Em termos de publicidade, que foi considerada excessiva, sentiu-se a necessidade de subtrair à avalią̧ão aquilo que "deve" ficar $\mathrm{cm}$ segredo, ou seja, a ação do Ministério da Defesa. Isso, entretanto, não impediu o Primeiro-Ministro Rocard de pedir uma auditoria externa sobre os programas militares. Verifica-se que, nos EUA, ocorreram as primciras avaliações dos estudos militares. E na Itália, também, registra-se a experiência recente do Comitê de avaliação da despesa militar junto ao Ministério da Defesa. 
19 Este Artigo estabelece que o Presidente da República nomeie, também, o Presidente do Cse. Isto modifica, assim, o Artigo 10 do decreto de janeiro, que atribui tais deveres ao Primeiro-Ministro. Nota-se que o Relatório de Viveret indica de quais órgãos de pesquisa deveriam participar os especialistas: eram os órgãos já atuantes no campo da avaliação, como o Centre scientifique et sechnique du batiment, o Comité national d'évaluation de la recherche, o Comité scientifique de l'office parlemantaire des choix technologiques et scientifiques, o Cnrs, o Centre de prospective et d'évaluation. Além disso, previa que o presidente fosse eleito pelos seus membros (VIVERET, 1989, p. 75). Os primeiros onze componentes - cujo elenco encontra-se no Cse (I993, p. 57) - são três professores universitários. quatro diretores dos centros de pesquisa, três conselheiros de Estado, um presidente de uma entidade de crédito privado. Foi nomeado o prof. Leca, que é uma prestigiosa figura independente do Institut de sciences politiques ( $\mathrm{cm}$ junho de 1993, ele recebeu a Légion d'homneur).

${ }^{20}$ No que diz respeito à formação dos especialistas, que depois scrão os "encarregados da avaliação", parece não ser necessário criar um doutorado em avaliação (doutorado nos Estados Unidos na Policy Analysis); sobretudo, se se considerar que as Grandes écoles, como Hautes éndes commerciales, a École nationale d'administration, deveriam acrescentar cursos de avaliação aos já existentes. Isso permitiria criar novos avaliadores que teriam tanıbém outras especialidades $\mathrm{e}$ que não fossem avaliadores tout court. No que se refere à formação contínua dos funcionários públicos, pode-se dizer que o Cse com a sua atividade desenvolva já atualmente esta tarefa.

21 Para certas avaliações isso pode não constituir um grave problema. Não partilho dos temores de DURAN c MonNier (1992), que falam a este propósito de "premissas teóricas instáveis" e "práticas hesitantes". Creio que a peculiaridade do modelo pluralista deveria ser a de reunir todas as posições, gerencial inclusive.

$22 \mathrm{O}$ seu esforço em manter-se informado sobre o desenvolvimento da avaliação na administração francesa e de participar diretamente através de scus membros relatores da avaliação feita por outros (Cse, 1993, p. 19).

${ }^{23}$ No II Relatório do Cse, Perret (1993, p. 76) observa que a origem da avaliação na França não é unitária mas pode ser reconduzida a quatro pólos principais de competência: os centros de pesquisas sociais, os escritórios de estudo dos ministérios e de outras empresas e corpos de inspeção c controle, o grupo dos especialistas.

24 Ao observar o primciro parecer sobre a avaliação da informaitica na administração, veremos que o principal conselho é o de reduzir as ambições teóricas $\mathrm{e}$ procurar tornar mais concreta a abordagem, por exemplo não pretendendo fazer uma avaliação abrangente de todos os instrumentos legislativos que introduziram a informática, mas fazendo uma profunda análise, em alguns casos, que possam servir tambẻm para outros de um modo analógico e objetivando encontrar medidas de contribuição que a informática possa dar à qualidade do serviço $\mathrm{c}, \mathrm{cm}$ particular, à simplicidade dos procedimentos.

${ }^{25}$ Esta problemática foi debatida na convenção Service public et usagers: vers quelles relations?, organizada $\mathrm{cm}$ Paris, $\mathrm{cm}$ janeiro de 1993, pelo Ministério da Função Pública c pelo Observatoire de la décision publique.

26 De uma entrevista com Sylvie Trosa, rapporteur adjoint do Cse, feita em maio de 1991.

${ }^{27}$ Sobre esta intenção democrática da avaliação vê-sc a ressonância que tiveram as idéias de Albert Hirschman nos ambientes do Commissariat Général du Plan. No encontro, organizado por Hirschman em novembro de 1992, o mesmo desenvolveu as idéias contidas no sexto capitulo de seu Retóricas da intransigência, que se referem a una retórica "progressista" e propôs uma idéia de democracia capaz de favorecer o debate c a negociação. Interferindo na discussão. De Foucauld comentou: "Tudo aquilo que disse Hirschman é fecundo c pode ser utilizado na avaliação das políticas públicas, que é sempre confrontada a casos concretos e deve servir de apoio às decisões". 
BARDACH, E. The implementation game: what happens after a bill comes a law. Cambridge: Mit Press, 1977.

Bonetti, M., Fraisse, J., de Gauleac, V. l'évaluation dynamique des orgamisations publiques. Paris: Editions d'Organisations, 1987.

Bounoon, R. Effets penvers et ordre social. Paris: Puf, 1977.

Boudon, R. “La rhćtorique est-clle réactionnaire?". Le débat, 69, 1992.

CAMpdel, D. "Reforms as Experiments." American Psycologist, vol. 24, April, 1969.

Cielimsky, E. Le cas americain. Paris: Fondation du Futur, 1988.

Chelimsky, E. Intervenção cm Ces c Odp, 1992.

COHEN, E., MUller, P. "Présentation". Revue française de science politique, 2, 1992.

Commissariat Gćnćral du Plan. Outils, pratiques, institutions pour èvaluer les politiques publiques. Paris: La Documentation française, 1990.

Commission nationale d'évaluation du revenu minimum d'insertion. Rmi. Le pari de l'insertion. Paris: La Documentation française, 1992.

Ces (Conseil économique et social). "L'évaluation des politiques publiques." Journal officiel de la République française: avis el rapports du Conseil economique et social, 2, Paris, 1991.

Ces (Conscil économique et social), Odp (Observatoirc de la décision publique). Première conférence nationale de l'évaluation des politiques publiques, Mimco, Paris, 1992.

Ces (Conseil scientifique de l'évaluation). L'évaluation de l'expertise à la responsabilité. Paris: La Documentation française, 1992.

Ces (Conseil scientifique de l'évaluation. Lévaluation en dèveloppement. Paris: La Documentation française, 1993.

Crozier, M. "Analyse sociologique de la planification française", PAlmade, G. (org.) liéconomie et les sciences humaines. Paris: Dunod, 1967.

Crozier, M. Etat modeste, état moderne. Paris: Fayard, 1987. Roma: Edizioni Lavoro, 1988.

Crozurer, M. Comment réformer l'État? Trois pays, trois stratégies: Surède, Japon, Etats Unis. Paris: La Documentation française, 1989.

Det.enu, M. (org.). Evaluer les politiques publiques: méthode, déontologie, organisation. Rapport pour le Commissariat Général du Plan. Paris: La Documentation française, 1989.

De Foucaui.d, J. B. Intervenção in Ces e Odp, 1992.

Duran, P., Monnier, E. "Le développement de l'évaluation en France. Nécessités icchniques et exigences politiques". Revue française de science politique, 2, 1992.

Fondation du Futur. Comment réformer l'état. Paris: Cahiers de la Fondation du futur, 1988.

Grémion, C. "Quelles méthodes pour évaluer la décentralisation?" Actualité Juridique -Droit Administratif, 1992.

Guba, E., Lincoln, Y. Fourth Generation Evaluations. Newbury Park: Sage Publications, 1989.

Lamarque, D. "Le rôle des instances d'évaluation." Conseil scientifique de l'évaluation, Paris, 1993.

Hirschiman, A. O. Retóricas da intransigéncia. Bologna: Il Mulino, 1991.

HiRSCIiman, A. O. "L'argument intransigeant comme idée reçue." Le débat, 69.

MAZEY, S. "Riforma politico-amministrativa e Stato francese: dall'affermazione al compromesso." Rivistu trimestrale di scienza dell amministrazione, 4, 1991.

Meny, Y., Tuloenig, J. C. Politiques publiques. Paris: Puf, 1989.

MinelLI, A. R. "Scienza dell'amministrazione e metodo comparato." FrEdDI, G. (org.). Scienza dell'amministrazione e politiche pubhliche. Firrenze: Nuova Italia, 1989. 
Ministère de la cooperation. Analyses critiques des méthodes d'évaluation des projets. Paris: Mimeo, 1976.

Monnier, E. Évaluation de l'action des pouvoirs publics. Paris: Economica, 1987.

MONNIER, E. "Évaluation des politiques publiques. Méthodes et pratiques", dossiêr de Problemes politiques et sociaux, 599. Paris: La Documentation française, 1989.

Monnier, E. "L'évaluation pluraliste: un usage nouveau d'outils classiques". Paris: Commissariat Général du Plan, 1990.

MONNIER, E. "Valutazione delle politiche pubbliche in Francia: applicazioni e paradigmi a confronto". Azienda pubblica, 1, 1992.

MULLer, P. Les politiques publiques. Paris: Puf, 1990.

Nioche, J.P, PoINSARD, R. l'évaluation des politiques publiques. Paris: Economica, 1985.

Padioleau, J. G. l.étal au concret. Paris: Puf, 1982.

Perret, B. "Le contexte français de l'évaluation". Paris: Conseil économique et social, 1993.

Pressman, J. L, Wildavsky, A. Implementation. Berkeley: University of California Press, 1973.

RosanVallon, P. La crise de lëlat providence. Paris: Scuil, 1981.

Stame, N. "Valutazione ex post $\mathrm{e}$ conseguenze inattese". Sociologia e ricerca sociale, 31 , 1990.

VIVERET, P. L'évaluation des politiques et des actions publiques et Propositions en vue de l'évaluation du revenu minimum d'insertion. Paris: La Documentation française, 1989.

Viveret, P. "Le citoyen et les deux "boîtes noires". Le débat, 71, 1992.

WEISS, C. Evaluation Research: Methods of Assessing Program Effectiveness. PrenticeHall, N. J.: Englewood Cliffs, 1972. 


\section{Avaliação das políticas públicas na França}

Nicoletra Stame Meldolesi

Após um longo periodo de discussão sobre a reforma do Estado, a França, en 1990 , implementou um sistema interdepartamental para a avaliação das politicas públicas.

$O$ aspecto interessante nesta reforma ć o meio pelo qual um pequeno grupo de pessoas, de diferentes instituiçōes e com experiências politicas distintas, convenceu-se da importância da avaliação das políticas públicas e se conscientizou dos diversos problemas relativos a esta questão. Finalnente, com uma atitude bipartidária, este grupo foi capaz de criar uma realidade que modifica profundamente o sistema legislativo, tanto no que se refere ao processo decisório quanto ao sistema de implementação das políticas.

Neste trabalho, o autor descreve os passos do debate e os recursos das diferentes propostas que acabaram por se transformar no projeto de reforma e na sua implementação.

\section{Evaluación de las politicas públicas en Francia Nicolerta Stame Meldolesi}

Tras un largo periodo de discusión sobre la reforma del Estado, se implantó en Francia, en 1990, un sistema interdepartamental para la evaluación de politicas públicas. El aspecto relevante de esa reforma es el hecho de que un pequeño grupo de personas, de diversas instituciones y de matices políticos distintos, se haya convencido de la importancia de la evaluación de las políticas públicas u se haya buscado tener conciencia de los diversos problemas relacionados a esta cuestión. En definitiva, este grupo, con una actitud bipartidaria, ha sido capaz de crear una realidad que modifica produndamente el sistema legislativo, tanto en lo que se reficre al proceso desisorio como al sistema de ejecución de las politicas publicas. En este trabajo, cl autor descrive los pasos del debate y los recursos de las diferentes propuestas que acabaron por transformarse en el projecto de reforma y en su puesta en marcha.

\section{Evaluation of the public policies in France Nicolerta Stame Meldolesi}

Following a decade-long discussion on the state reform, in 1990, France implemented an interdepartmental system for the assessment of public policies.

The interesting element on this reform is the way through which a small group of persons, coming from different institutional and political experiences, convineed himself of the importance of policy and made them aware of the different problems involved and was finally able, with a bipartisan attitude, to crate a reality which deeply modifies the legislative system, both in the decision-making and in the implementation system. 